\title{
A case of scientific misconduct
}

In December 1997 a paper entitled "Relation between solar radio bursts and sudden enhancement (or fall) of atmospherics over the regular behaviour of the noise level" was received from A. B. Bhattacharya et al., submitted for publication in Annales Geophysicae. On instruction from the Topical Editor for Ionospheric Physics (D. Alcaydé), the paper was sent by the office to two referees in the usual manner. One of these referees subsequently contacted the Editor-in-Chief (S.W.H. Cowley) with concerns about the originality of the paper, pointing out that a paper of very similar content with the same lead author had previously been published in the Indian Journal of Radio and Space Physics (A.B. Bhattacharya and R. Bhattacharya, Effect of solar flare on the field intensity of VLF atmospherics, Indian J. Radio Space Phys., vol. 12, pp. 56-58, 1983). These concerns were therefore carefully and independently investigated both by the Editor-in-Chief and the Topical Editor for Ionospheric Physics, who subsequently agreed that much of the text was indeed copied from the 1983 paper, with only a short additional paragraph in the new submission. However, the previously-published paper was not referenced in the submitted paper. This in itself was considered unacceptable, but worse was the fact that the details of the scientific case and the figures showing the data which supported it had been altered and falsified. Specifically, a figure showing radio measurements was clearly a copy of one published in the 1983 paper, but had been post-dated and described as relating to a 1996 flare event. The related radio frequencies had also been modified.

The Editor-in-Chief and Topical Editor for Ionospheric Physics thus agreed that this was a matter of the utmost seriousness which needed to be taken up with the authors, and, when no satisfactory explanation was forthcoming, also with institute authorities. Our evidence of misconduct was sent to Kalyani University, West Bengal, India, on 27 February 1998. An enquiry by a committee set up by the university reported, 18 months later, that "In conclusion, the Sub-Committee finds that the defence put forward by Dr. A.B. Bhattacharya against the charges levelled by the Editor in Chief of Annales Geophysicae is completely inadequate".

Falsification of scientific results strikes at the heart of the scientific enterprise. In October 1999, the US White House Office of Science and Technology Policy defined scientific misconduct as "fabrication, falsification, or plagiarism in proposing, performing, or reviewing research, or in reporting research results". The case that we have described here undoubtedly falls into this category. We felt it to be our unpleasant duty to report it as such to the scientific community.

Denis Alcaydé

Editor-in-Chief, formerly Topical Editor for Ionospheric Physics

Stanley W.H. Cowley Formerly Editor-in-Chief 